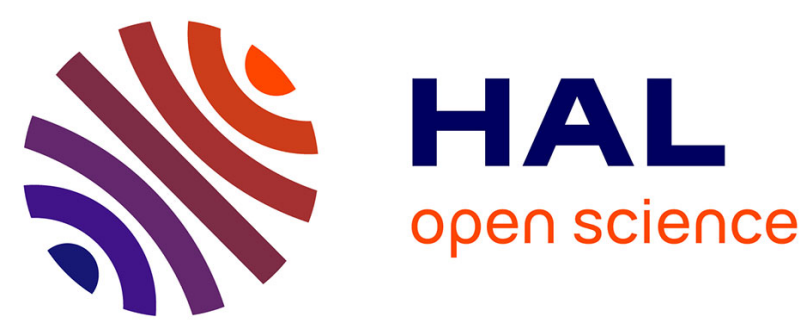

\title{
New Multiparametric Analysis of Cardiac Dyssynchrony: Machine Learning and Prediction of Response to CRT
}

Erwan Donal, Arnaud Hubert, Virginie Le Rolle, Christophe Leclercq, Raphael Martins, Philippe Mabo, Elena Galli, Alfredo Hernandez

\section{- To cite this version:}

Erwan Donal, Arnaud Hubert, Virginie Le Rolle, Christophe Leclercq, Raphael Martins, et al.. New Multiparametric Analysis of Cardiac Dyssynchrony: Machine Learning and Prediction of Response to CRT. JACC: Cardiovascular Imaging, 2019, 12 (9), pp.1887-1888. 10.1016/j.jcmg.2019.03.009 . hal-03166749

HAL Id: hal-03166749

https://hal-univ-rennes1.archives-ouvertes.fr/hal-03166749

Submitted on 11 Mar 2021

HAL is a multi-disciplinary open access archive for the deposit and dissemination of scientific research documents, whether they are published or not. The documents may come from teaching and research institutions in France or abroad, or from public or private research centers.
L'archive ouverte pluridisciplinaire HAL, est destinée au dépôt et à la diffusion de documents scientifiques de niveau recherche, publiés ou non, émanant des établissements d'enseignement et de recherche français ou étrangers, des laboratoires publics ou privés. 


\title{
LETTER TO THE EDITOR
}

\section{New Multiparametric Analysis of Cardiac Dyssynchrony: Machine Learning and Prediction of Response to CRT}

\author{
Erwan Donal, $M D, P h D^{*} \downarrow$ \\ Arnaud Hubert, $M D \diamond$ \\ Virginie Le Rolle, PhD \\ Christophe Leclercq, MD, PhD \\ Raphael Martins, $M D, P h D$ \\ Philippe Mabo, $M D, P h D$ \\ Elena Galli, MD, PhD \\ Alfredo Hernandez, PhD
}

Univ Rennes, CHU Rennes, Inserm, LTSI - UMR 1099, F-35000 Rennes, France

\author{
E-mail:erwan.donal@chu-rennes.fr \\ Service de Cardiologie University Hôpital Pontchaillou Centre Cardio-pneumologique Rennes 35000, France \\ https://doi.org/10.1016/j.jcmg.2019.03.009
}

Please note: The authors have reported that they have no relationships relevant to the contents of this paper to disclose.

$\checkmark$ Drs. Donal and Hubert contributed equally to this manuscript.

Although previous studies have suggested that the analysis of mechanical dyssynchrony can improve prediction of response to cardiac resynchronization therapy (CRT), current guidelines still neglect the value of left ventricular (LV) mechanical dyssynchrony assessed by imaging technics, particularly echocardiography. Recently, machine-learning methods have offered new opportunities to analyze complex features in cardiology (1). We hypothesized that a multiparametric evaluation, based on the combination of electrocardiographic and echocardiographic parameters, analyzed by an automated machine-learning system based on the random forest (RF) method, could enhance the appraisal of the likelihood of reverse remodeling and prognosis of favorable clinical evolution after CRT.

A total of 154 heart failure patients, with an ejection fraction $<35 \%$ and QRS duration $>120 \mathrm{~ms}$, who had a CRT device implanted in Rennes University Hospital between 2010 and 2017, were retrospectively studied. A total of 109 patients $(71 \%)$ were responders, defined by a decrease in LV endsystolic volume $>15 \%$ at 6 -month follow-up. The mean age of the overall population was $65 \pm 10$ years, there were 103 (67\%) men. Mean QRS width and LV ejection fraction were $164 \pm 18 \mathrm{~ms}$ and $28 \pm 7 \%$, respectively. Ischemic cardiomyopathy was identified in $45(29 \%)$ patients. All patients had a complete baseline echocardiography before implantation (Ve9, Ve95, GE Healthcare, Horten, Norway) and at 6month followup, with offline parameters measurement according to the current guidelines by a certified senior echocardiographer. Custom-made signal processing methods, developed with MATLAB software (MathWorks Inc.), were used to analyze automatically the 4-chamber longitudinal strain, providing 60 different features, particularly dyssynchrony parameters and integrals of regional longitudinal strain signals, as described in Bernard et al. (2). QRS duration was also included in the analysis as an additional feature. Electrocardiogram (ECG) and echocardiographic parameters were selected first, based on a filtering cutoff of Pearson's coefficient $>0.8$. The R) method was then applied to analyze the relative importance of the remaining features and to obtain the 6 most significant features. A final RF method was applied to the 6 selected features, with the objective of predicting response to CRT. A Monte Carlo crossvalidation method with 30 runs was applied, using, in each run, different random sets of $70 \%$ of patients for training and $30 \%$ for testing.

Results showed a mean area under the curve (AUC) of 0.804 with a standard deviation of 0.03 (0.77 to 0.94) (Figure 1). In contrast, the best classification performance for a single variable was obtained with a strain-based measurement of myocardial wasted energy of the septal wall, with an AUC of 0.686, followed by QRS duration with an AUC of 0.668 . 
Our study demonstrates that the machine-learning approaches may be useful to improve the estimation of good candidates for CRT. Linear models are useful to find variables that are significantly different between groups, but these variables are not necessarily associated with outcomes. Through the iterative creation of models from a significant number of variables, machine learning allows the identification of the model that best fits the primitive clinical question. It optimally combines complementary information on the patients' susceptibility to respond favorably to a predefined treatment $(3,4)$. Combing multiple data might allow a move to "precision medicine" (5). Moreover, this study underlines the complementary value of LV dyssynchrony parameters with respect to standard ECG analysis and proposes a method to estimate CRT response by combining a limited number of sensitive ECG and echocardiography parameters. Finally, this approach demonstrated that a fast semiautomated echocardiographic method, based only on a longitudinal strain curves that is strongly reproducible even for novice readers, could provide useful information to better select CRT candidates. Although our population is limited, the Monte Carlo cross-validation method is robust through many tests using subgroups for learning and a subgroup for testing.

When analyzed in a multiparametric approach using machine-learning algorithms, a combination of echo-based parameters of LV dyssynchrony and QRS duration helped to improve the prediction of the response to CRT.

\section{REFERENCES}

1. Salem Omar AM, Shameer K, Narula S, et al. Artificial intelligence-based assessment of left ventricular filling pressures from 2-dimensional cardiac ultrasound images. J Am Coll Cardiol Img 2018;11:509-10.

2. Bernard A, Donal E, Leclercq C, et al. Impact of cardiac resynchronization therapy on left ventricular mechanics: understanding the response through a new quantitative approach based on longitudinal strain integrals. J Am Soc Echocardiogr 2015;28:700-8.

3. Cikes M, Sanchez-Martinez S, Claggett B, et al. Machine learning-based phenogrouping in heart failure to identify responders to cardiac resynchronization therapy. Eur J Heart Fail 2019;21:74-85.

4. Kalscheur MM, Kipp RT, Tattersall MC, et al. Machine learning algorithm predicts cardiac resynchronization therapy outcomes: lessons from the COMPANION Trial. Circ Arrhythm Electrophysiol 2018;11:e005499.

5. Califf RM. Future of personalized cardiovascular medicine: JACC State-ofthe-Art Review. J Am Coll Cardiol 2018;72:3301-9.

\section{Figure 1}

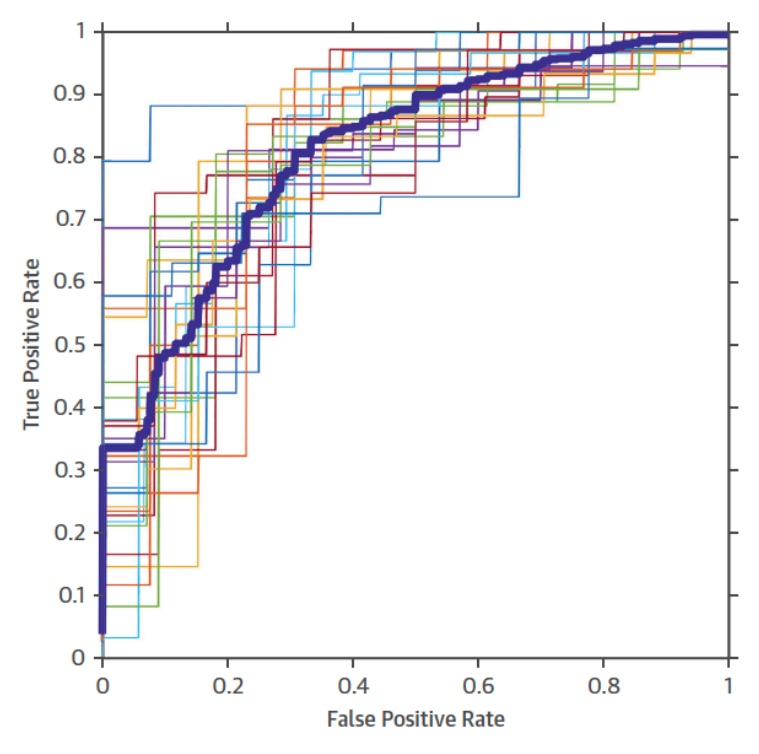

This was done for 30 runs of the Monte Carlo method (lighter lines) and mean ROC curve for the 30 runs (bold line), showing detection performance for the prediction of the response to the therapy. $\mathrm{ROC}=$ receiver operating characteristic. 